\title{
EL DELITO AMBIENTAL. REFLEXIONES DESDE EL DERECHO ADMINISTRATIVO
}

\author{
POR \\ R. Martín Mateo
}

\begin{abstract}
SUMARIO: I. EL BIEN JURIDICO PROTEGIDO: A) El ambiente en cuanto objeto sustantivo del Derecho. B) Los elementos naturales implicados. C) Conceptos conexos: a) Recursos naturales; b) Calidad de vida. D) La determinación legal: a) La Constitución; b) El Código Penal.-II. LA TUTELA JURIDICO-PENAL Y EL SISTEMA DE FUENTES: A) El reenvio penal normativo. B) La legislación administrativa: a) Las Comunidades Europeas; b) Normativa estatal; c) Comunidades Autonomas; d) Municipios.III. LA APARENTE INEFICACIA DEL DELITO AMBIENTAL: A) Las dificultades presentes. B) Los atentados ambientales no cubiertos.
\end{abstract}

\section{EL BIEN JURIDICO PROTEGIDO}

De acuerdo con una metodología que me parece obligada para el análisis de los ordenamientos sectoriales, conviene contrastar en este tipo de operaciones lógicas los dictados del legislador con las características de la realidad social a conformar, en nuestro caso las conductas humanas incidentes sobre el ambiente, lo que nos permitirá orientar la aplicación de las normas en juego, y valorar su aptitud para el logro de los objetivos perseguidos.

Este tipo de indagaciones (1) debe partir por supuesto de los pronunciamientos de la Constitución, como ha hecho ciertamente la doctrina penalista que ha abordado el tema que nos ocupa, encabezada por Rodríguez Ramos (2), y que cuenta también con otras meritorias contribuciones, . como se verá, entre las que destacamos la de De la Cuesta Arzamendi (3). Pese a la indiscutible

(1) El presente estudio debe mucho a la ayuda que ha sido prestada a su autor por J. J. Díaz, joven $y$ valioso penalista con el que por otras razones tengo contraída también una importante deuda de agradecimiento.

(2) Vid. de este autor «Instrumentos jurídicos preventivos y represivos en la protección del medio ambiente», en Documentación Administrativa núm. 190, 1982, pp. 463 y ss.; "Presente y futuro de la protección penal del medio ambiente en Españan, en COBO DEL ROSAL Comentarios a la legislación penal, I, Madrid, 1982, pp. 259 y ss., y especialmente "Delitos contra el medio ambientew, en La reforma del Código Penal de 1983, Edersa, Madrid, 1985, pp. 828 y ss.

(3) "La ley alemana de reforma del Código Penal para la lucha frente a la criminalidad contra el ambiente», en Cuadernos de Política Criminal núm. 18/1982, pp. 652 y ss., y «Protección 
primacía de esta norma jurídica, sus mandatos lógicamente están concebidos con una cierta amplitud, lo que es el caso del artículo 45 que la Constitución española dedica al ambiente cuya redacción en todo caso pudiera haber sido más afortunada (4).

\section{A) El ambiente en Cuanto objeto sustantivo del Derecho}

Múltiples acepciones del ambiente pueden tener relevancia jurídica, "ambiente de tolerancia», "ambiente artístico», e incluso "ambiente criminógeno», como el consumo de drogas. Pero la versión que aquí nos interesa es la difundida a partir del Congreso de Estocolmo de 1972, de la que indudablemente se hace eco nuestra Constitución en el artículo mencionado, y que recibe concreción positiva en el artículo 347 bis del Código Penal.

Es pues necesario describir y precisar el ambiente al que aluden las disposiciones mencionadas $y$ al que justamente la doctrina penalista asigna propia sustantividad en cuanto bien jurídico autónomo, diferenciable de otros como la salud, con propia entidad penal (5).

La realidad ambiental, en lo que respecta a su moderna transcendencia para el Derecho, es sin embargo técnicamente difícil de acotar, lo que explica así las dificultades de la doctrina y del propio legislador, cuyos asesores comparten a veces la misma perplejidad, lo que luce no sólo en los textos jurídicos nacionales, sino también en los pronunciamientos de las organizaciones internacionales (6).

penal de la ordenación del territorio y del ambiente, Tít. XIIILII PANCP 1983», en Documentación Jurídica, monografía dedicada a la propuesta de Anteproyecto de nuevo Código Penal, vol. 2/1983; Ecología y Derecho Penal, en BERISTAIN; DE LA CUESTA: La droga en la sociedad actual, San Sebastián, 1986, pp. 277 y ss. Es de destacar que este joven tratadista ha realizado también por su sólida aportación de Derecho comparado, particularmente alemán, vid. del mismo "La Ley alemana de reforma del Código Penal para la lucha frente a la criminalidad contra el ambiente», en Cuadernos de Política Criminal núm. 18/1982, y "Protección internacional del medio ambiente y derecho ecológicon, en Cursos de verano de San Sebastián, s/f, pp. 125 y siguientes.

(4) Me remito a mi trabajo "Ambiente y recursos naturales. El sistema institucional», en Revista de Derecho Urbanístico núm. 95/1985, pp. 871 y ss.

(5) Vid. al respecto RODRIGUEZ RAMOS: "Delitos contra el medio ambiente», loc. cit., p. 830; RodRígUEZ DEVESA: «Derecho penal español. Parte especial», 10. ${ }^{a}$ ed., Dykinson, Madrid, 1987, p. 1.101; BoIX: "Delitos contra el medio ambiente», en COBO DEL ROSAL y otros, «Derecho Penal. Parte especial», vol. I, Tirant lo Blanch, Valencia, 1987, p. 368, y PERIS: Delitos contra el medio ambiente, Valencia, 1984

(6) Vid. por ejemplo y en relación con el desmesurado criterio de las primeras formulaciones de política ambiental de la CEE, mi trabajo «EI concepto de ambiente en la CEE», en Informaciones de la CEE núm. 14/1986, pp. 47 y ss. 
Pese a la indudable complejidad de esta materia el ambiente no es necesariamente un bien indefinido (7) cuyo aislamiento temporal sea imposible. Más bien creemos que tal tarea, no sólo es factible sino inexcusable, aunque para ello deberá recurrirse al concurso de los científicos de la naturaleza, y especialmente a los ecólogos (8). El inevitable recurso a fuentes extrajurídicas para precisar las circunstancias del injusto penal, produce comprensibles perplejidades e inseguridades en los medios penalistas, como se ha planteado en Alemania (9).

El concepto de que aquí partimos no tiene, evidentemente, en lo que al Derecho se refiere, un alcance apodíctico. El legislador está por supuesto en disposición de incluir lo que le parezca bajo la rúbrica en cuestión, pero es labor del jurista superar los nominalismos y tratar sistemáticamente un dispositivo normativo que con una metodología homogénea se propone disciplinar conductas bajo un propósito común.

Es posible, reiteramos, introducir en el mismo saco jurídico una serie de medidas relativamente descoordinadas y que instrumentan políticas heterogéneas, pero ello no transcenderá a la eficacia social del Derecho. Así, por ejemplo, la protección de la fauna tiene reglas propias concordes con el ciclo biológico de las distintas especies que nada tiene que ver con los mecanismos de la contaminación atmosférica, aunque por supuesto una polución excesiva arruine la vida de los animales.

El ambiente es a mi juicio un concepto fundamentalmente fisico (10) en cuanto entorno natural de los sujetos y propiciador de la vida, aunque puede ser modificado por el hombre dentro de ciertos límites que remiten a su vez a cánones conservacionistas históricamente cambiantes. Dejamos por ello de lado otras comprensiones que relacionan este concepto con objetivos socioeconómicos, políticos o culturales, que nada tienen que ver con el

(7) Así Cainiello: "Aspetti juiridicci della tutella dell'ambiente», en Archivo Guiridico "Filippo Serafini», 1982, p. 365.

(8) Por todos MARGALEF: «Ecología», Planeta, Barcelona, 1981, para quien la ecología, siguiendo a Haeckel, 1870, constituye un sistema de elementos interrelacionados describiendo a «la naturaleza en términos de materia, energía y organización», p. 17. En parecidos términos su edición in extenso Ecología, Barcelona, Omega, 1971. Otros clásicos modernos en la materia se expresan en análogo sentido, asi ODUM: Ecología, trad. esp., México, 1964, y WATT: Ecology and Resource Management, McGraw Hill, New York, 1968.

(9) DE LA CUESTA: Protección Penal, cit., p. 922.

(10) Criterio en el que coincide, terminológicamente al menos, DE LA CUESTA: «Protección penal de la ordenación del territorio y del ambienten, loc cit., p. 879. Este autor adopta una solución intermedia aunque no omnicomprensivo, invocando la autorizada opinión del académico C. J. de Cela y de Fuentes Bodelón, quien recuerda el rechazo de la doctrina hispanoamericana a la incorrección gramátical que supone la rúbrica umedio ambiente» habitual en España «Planteamientos previos para una formulación de un Derecho Ambiental», en Documentación Administrativa, en 190, 1981, p. 113. 
mantenimiento del equilibrio ecológico y que por supuesto requieren la aplicación de medidas sustancialmente diferentes.

En principio coincidiría con Rodríguez Ramos, en relacionar valor jurídico ambiental con los condicionantes básicos necesarios «para el mantenimiento de la vida en general $y$ de la humana en particular», si bien no comparto la ampliación de estos valores, conectándolos con los niveles de renta (11).

La mayoría de los penalistas se inclinan también por una comprensión física del ambiente (12), tesis que por supuesto asumen todos los administrativistas (13), señalándose la inoperancia que supondría adicionar otro tipo de factores como los socioeconómicos y culturales ya indicados, lo que a la postre arrastraría todas las responsabilidades del Estado, dado que nada sería extraño al medio ambiente (14). Algunos autores, aun manteniéndose en el entorno físico, incluyen aquí también el medio creado por el hombre, el urbano, lo que rechazamos ya que esta problemática responde a otros planteamientos y reglas (15).

\section{B) LOS ELEMENTOS NATURALES IMPLICADOS}

No todos los factores naturales deben estar sometidos a la tutela específica que realiza el denominado Derecho ambiental. Sólo aquellos que tengan una decisiva importancia para el hombre y el resto de seres y sean susceptibles de intervenciones homologables se integrarán en este núcleo especialmente protegido, cuyos componentes tienen los siguientes caracteres:

- Trascendencia básica para la vida en cuanto que sin ellos sería imposible la existencia animada en la biosfera (16).

- Comportamiento dinámico en cuanto que se integran en los

(11) "Delitos contra el medio ambiente», p. 829. Este autor no obstante tiene presente que el "medio ambiente», siguiendo la terminología constitucional, remite a los recursos naturales, apoyando la extensión comentada en base a la remisión que desorientadamente realiza la Constitución al desarrollo de la personalidad sobre lo que luego volveremos.

(12) Así, DEVESA: "Delitos contra el medio ambiente», loc. cit., p. 1.103 , y PERIS: "Delitos contra el medio ambiente», Boix, op. cit., p. 369.

(13) Entre los autores clásicos ya en estos temas, LAMARQUE: «Droit de la protection de la nature et de l'environment», en LGD, París, 1973, y DEXPASS: "Droit de l'environment», en LITEC, París, 1980.

(14) Así, LÓPEZ RAḾ́n: uldeas acerca de la intervención administrativa sobre el medio ambiente», en Documentación Adminitrativa núm. 190/1981, p. 39. En parecido sentido DEXPASS: "Droit de l'environment", cit., p. IX.

(15) Asi, GIANNINI: "Ambiente: saggio sui diversi aspetti guiridicci», en Almerigui; ALPA: Diritto e ambiente. Materiali di dottrina e guirisprudenza, parte I. Diritto Civile. Cedam Padova, 1984, pp. 37 y ss., y DiEZ-PICAZO: Fundamentos del Derecho Civil patrimonial, vol. II, Madrid 1983, p. 33.

(16) En este sentido, definitivamente, RODRígUEZ DEVESA que alude a «los elementos naturales cuya conservación o restauración es indispensable para la supervivencia humanal, en Derecho penal, p. 1103. 
distintos sistemas naturales de los que forman parte, interaccionado a su vez entre sí.

- Posibilidad de que la incidencia sobre ellos de conductas humanas de fundamentación económica excedan de su capacidad de autorregeneración.

- Enfasis consiguientemente preventivo y subsidiariamente represivo y compensador de las disposiciones públicas que regulan las conductas implicadas.

Es claro que con ello nos estamos refiriendo a dos sistemas fundamentales, el del agua y el del aire, a través de los cuales pueden transmitirse agresiones de muy diverso tipo: Sonoras, químicas, radiactivas, etc. (17).

Probablemente haya que añadir también el suelo en cuanto que si bien es a menudo objeto pasivo de atentados vehiculizados a través del agua o del aire; lluvia ácida, mineralización por regadíos, es también plataforma de perturbaciones que a su vez inciden en los otros medios: desertificación por incendios o talas abusivas, lo que modifica el régimen de precipitaciones con trascendencia eventualmente mundial: eliminación de la selva tropical, que también afecta a la composición de la atmósfera al disminuir, vía acción clorofílica y respiración de las plantas, disminución de la proporción de algunos componentes esenciales: oxígeno, y el aumento de la de otros perjudiciales: anhídrido carbónico. Dentro de este subepígrafe ambiental, cabe incluir las medidas que afectan a la restauración de suelos afectados por canteras, excavaciones mineras (18) y otras alteraciones artificiales del medio territorial.

Queda fuera de este esquema algunas acciones potenciales sobre el medio que aunque no se transmitan a través de los expresados sistemas pueden tener a escala planetaria negativas $e$ incluso catastróficas consecuencias, cual es el caso de las modernas investigaciones, experimentaciones y aplicaciones propias de la biotecnología, lo que ha suscitado ya reacciones preventivas en medios nacionales (19) e internacionales (20). Pero no se conoce hasta la fecha ninguna consecuencia concretamente dañosa de

(17) Con más precisiones en mi monografía «Derecho ambiental», IEAL, Madrid, 1977, pp. 79 y ss. También LÓPEZ RAMÓN: La conservación de la naturaleza: los espacios naturales protegidos, Colegio de los Españoles de Bolonia, Zaragoza, 1980, p. 39.

(18) Tema éste magistralmente tratado entre nosotros por QUINTANA: "La repercusión de las actividades mineras en el medio ambiente. Su tratamiento jurídicon, Montecorvo, Madrid, 1987. Igualmente FERNÁNDEZ-ESPINAR: «El conflicto entre el medio ambiente y el desarrollo del sector mineron, en Revista de Administración Pública núm. $111 / 1986$, pp. 237 y ss.

(19) Vid. mi obra "Bioética y Derecho», Ariel, Barcelona, 1987.

(20) Caso de la CEE como refleja el Cuarto Programa en materia del ambiente 1987-1992 que se ocupa de ulas relaciones entre protección del medio y biotecnología», COM(86) 485 final, Bruxelles, 8 de octubre de 1986, pp. 43 y 79. 
estas prácticas, por lo que parece puede hacerse confianza en las medidas ya operativas instauradas, que en el país pionero en esta materia, Estados Unidos, caen por cierto bajo la responsabilidad de la EPA, Agencia Federal de Protección del Ambiente. Por otra parte, estos dispositivos de protección, también de énfasis preventivo, tienen poco que ver con las estrategias que se suscitan para la protección del aire, agua y suelo.

\section{C) CONCEPTOS CONEXOS}

Relacionados con el ambiente aparecen una serie de nociones - correspondientes, bien al campo de las ciencias sociales: calidad de vida, entorno humano; bien al de las ciencias de la naturaleza: recursos naturales, ecología, sistemas naturales; o mixtas: medio ambiente industrial, paisaje. Vamos a circunscribirnos sólo aquí a dos conceptos que han tenido acogida en la Constitución española.

\section{a) Recursos naturales.}

Constituyen el género al que pertenecen los elementos integrantes del ambiente, responden por tanto a una noción más amplia que la de éste, por lo que, atendiendo a las aludidas peculiaridades de tratamiento jurídico, la doctrina suele diferenciar sistemáticamente los respectivos análisis (21).

Los recursos naturales se clasifican en dos grandes grupos: renovables y no renovables, los primeros incluyen principalmente la energía solar y después los componentes básicos apoyados en ella que hacen posible la vida en la biosfera y a que nos hemos referido. Como consecuencia de todo ello aparecen los seres vivos, incluido por supuesto el hombre. Algunos de los recursos naturales renovables son objeto de especial protección por especies, caso de la ballena a escala internacional, o por áreas territoriales, zonas húmedas (22).

Los recursos naturales no renovables son los inertes incluidos en la litosfera o en los mares que por su accesibilidad y posibilidad de explotación tienen relevancia económica. Revisten poco interés a nuestros efectos, aunque deberían ser objeto de otro tipo de

(21) Así, CANO: «Derecho, Política y Administración ambientales», Depalma, Buenos Aires, 1978. La prestigiosa REVISTA argentina que este tratadista dirige, se denomina correctamente Ambiente y Recursos Naturales. También LAMARQUE: Droit de la protection de la nature et de l'environnement, cit.; CANO apunta que convendría seguramente revisar esta denominación para aludir a la naturaleza sin más ya que el Derecho tiene que estudiar temas que desbordan la noción de los recursos: inundaciones, ciclones, terremotos, etc., REVISTA, cit., núm. 3/1984, p. 122.

(22) Vid.: LÓPEZ RAMÓN: La conservación de la naturaleza: los espacios naturales protegidos, 1980, cit., y SOSA WAGNER: «Espacios naturales protegidos y Comunidades Autónomas», en Revista Española de Derecho Administrativo núm. 36/1983, pp. 343 y ss. 
intervenciones, especialmente apremiantes en el caso de los que en un periodo relativamente corto se agotarán, caso de los hidrocarburos que hoy sustentan la vida económica de todos los países. Desgraciadamente las medidas a adoptar son de alcance internacional y la Humanidad, como es sabido, no está suficientemente organizada a estas escalas.

b) Calidad de vida.

Se trata de un parámetro cuya generalización $y$ difusión es relativamente nueva a partir, a mi juicio, de la Conferencia de Estocolmo. Su relevancia jurídica, como he tratado de demostrar en otro trabajo (23), únicamente parece tener sentido en relación con el ambiente con el que este concepto, en su corta historia, aparece siempre asociado.

Se trataría de un criterio valorativo del ordenamiento ambiental, o que amplía el manejo de los recursos naturales más allá de las exigencias intrínsecas de conservación de las condiciones básicas de vida, para intentar adicionar un plus de bienestar a los ciudadanos: paisaje, luminosidad, acústica, aromas, etc.; como lúcidamente se ha detectado en medios penalistas, una cosa es tutelar la calidad de vida y otra la vida misma en el planeta (24).

\section{D) LA DETERMINACIÓN LEGAL}

El ordenamiento español contiene dos pronunciamientos capitales sobre la problemática ambiental, el contenido en el artículo 45 de la Constitución y el que recoge el artículo 347 bis del Código Penal. Vamos a analizar brevemente estos dos preceptos en relación con su posible acomodación a la comprensión del derecho ambiental que propugnamos.

\section{a) La Constitución.}

Estimo que la Constitución española recoge el modelo físiconatural del ambiente, aunque lógicamente le conecta con el hombre, ya que este texto incluye un catálogo de derechos, deberes e instituciones relacionados con el ciudadano. Ello no empece el que tenga en cuenta el ambiente en cuanto tal, dada la indudable coincidencia de intereses de los de la naturaleza en su conjunto en

(23) "La calidad de vida como valor jurídico», en Homenaje a García de Enterría, en prensa, parcialmente también en este sentido PÉREZ MORENO: La ordenación jurídica de la calidad de vida, en 16 Seminario Internacional del FEAN, octubre 1987, p. 9. Ponencia fotocopiada que he manejado por amabilidad de su autor.

(24) RODRiguez DeVeSA: Derecho Penal español, p. 1103. 
cuanto a las condiciones básicas para la vida de todos los seres, y del hombre, un ser animado más.

El hecho de que se conecte finalistamente «el derecho a disfrutar de un medio ambiente adecuado» con el desarrollo de la personalidad, no implica que para este precepto deban tutelarse todas las condiciones adecuadas a tal desarrollo, sino únicamente las de carácter natural. La propia sistemática de la Constitución y la ubicación de este artículo así lo postulan, ya que otros artículos se ocupan de las circunstancias de índole social que propician el desarrollo armónico de la personalidad: educación, deporte, cultura, seguridad social, etc.

Podrá convenirse en que efectivamente la Constitución adopta aquí una concepción del medio ambiente «moderadamente antropocéntrica» (25), pero no creemos, como se ha anticipado, que remita a valores sociales, ni tampoco que la protección de este medio tenga un sentido instrumental en cuanto al derecho del ciudadano a su disfrute (26) si con ello se quiere decir que la tutela constitucional del ambiente se agota en las consecuencias de éste para el hombre.

El párrafo segundo del artículo 45 establece como obligación autónoma de los poderes públicos velar «por la utilización racional de todos los recursos naturales» con el fin de defender y restaurar el medio ambiente. Hay aquí un deber a cargo de los poderes públicos concretable por las leyes, que afecta al "medio ambiente» en cuanto tal y a los imperativos de la lógica natural que le atañen, lo que puede coincidir con las exigencias del desarrollo de la personalidad de un individuo concreto, pero puede relacionarse con requerimientos de la comunidad nacional: contaminación fluvial; plurinacional: transmisión fronteriza de la polución; o planetaria: vertidos de alta radiactividad en los mares.

Lo que si tiene claras connotaciones antropológicas es el juego del criterio que el mismo artículo maneja de "la calidad de vida», que debe entenderse referido a la humana y no a la vida en general, $y$ que es susceptible por cierto de graduaciones valorativas en función de su mayor o menor complejidad o de las condiciones del entorno.

La utilización que el artículo 45.2 de la Constitución también hace de este contraste para juzgar la racional utilización de los recursos naturales, implicando a todos ellos y no sólo a los que soportan el ambiente en sentido técnico, descarta también aquí la posibilidad de entender la calidad de vida, fuera del marco físico,

(25) Rodríguez Ramos: Protección penal del ambiente, loc. cit., p. 261.

(26) BoIX: Delitos contra el medio ambiente, loc. cit.. o. 369. 
como complitud compleja del bienestar mediante la integración de diversos factores sociales, políticos y económicos. La Constitución sí se plantea en su Preámbulo este desiderátum gratificante, con escasa transcedencia jurídica como se comprenderá al proclamar la voluntad nacional de upromover el progreso de la cultura y de la economía para asegurar a todos una digna calidad de vida» (27).

b) El Código Penal.

El nuevo artículo 347 bis del Código Penal, introducido tras la reforma de 1983, aparece incluido en la Sección correspondiente a los delitos contra la salud pública y el medio ambiente en el capítulo «De los delitos de riesgo en general» (28).

Este precepto, cuya redacción ha suscitado justificadas críticas por parte de los tratadistas del Derecho penal, es sin embargo extraordinariamente afortunado en cuanto a la precisión de lo que sea el "medio ambiente» y lo que se considere como utilización racional de los recursos naturales que puede implicarle.

Para el Código Penal el "medio ambiente» está constituido, tal como se propugna desde las ciencias de la naturaleza, por los elementos fundamentales para la vida: la atmósfera, el suelo, las aguas terrestres y marítimas, y lo que reprime es la posibilidad de que estos vectores resulten contaminados mediante emisiones $o$ vertidos perjudiciales para la salud humana o para la vida animal o vegetal (29). El Código después de la reforma sintoniza así, afortunadamente, con la sistemática clásica del ambiente y con la tipología básica de las conductas que sería conveniente erradicar (30).

Desgraciadamente no bastaba con la recepción correcta de los presupuestos básicos de la reacción penal, la ausencia de las necesarias precisiones sobre las características de las conductas perseguibles y de sus resultados han hecho de esta figura delictiva una medida bastante ineficaz.

(27) Por cierto que de este pronunciamiento deduce Casabo la importancia que la Constitución otorga a la protección del medio ambiente como bien fundamental, quizá influido por las numerosas y reiteradas asociaciones que otros textos realizan de ambos conceptos, "La calidad normativa de las Comunidades Autónomas en la protección penal del medio ambiente», en Estudios penales y criminológicos, vol. V. Universidad de Santiago de Compostela, 1980-1981, p. 239.

(28) Sección II del capítulo II del título V del libro II del Código.

(29) La diferenciación que a estos últimos efectos se realiza entre «bosques, espacios naturales o plantaciones útiles» es ciertamente caprichosa y reiterativa, RODRIGUEZ RAMOS: Delitos contra el medio ambiente, loc. cit., p. 838, y escasamente inequívoca RODRIGUEZ DEVESA: Derecho Penal, p. 1107, habría bastado con aludir simplemente a la fauna y la flora.

(30) Cuadra perfectamente en cuanto a los lineamientos generales con la metodologia de mi libro Derecho ambiental, 1977, por lo que desde mis propias convicciones he anticipado un juicio positivo a la Reforma, Ambiente y recursos naturales. El sistema institucional, 1985, sólo la problemática del suelo que no se agota en su perturbación por emisiones parece insuficientemente tratada.

REVISTA DE ESTUDIOS. -2 


\section{LA TUTELA JURIDICO-PENAL Y EL SISTEMA DE FUENTES}

El último párrafo del artículo 45 de la Constitución ordena el establecimiento "de sanciones penales o en su caso administrativas» que afectarán a quienes violen lo dispuesto en el apartado anterior. El carácter alternativo a que esta redacción responde (31) hace concluir que no necesariamente todas las infracciones relacionadas con la protección ambiental habrán de ser sancionadas por ley penal, aunque estas medidas en el caso español deban ser introducidas por Ley Orgánica si afectan a las libertades públicas (32). Pero la Ley difícilmente puede agotar la materia al estar implicadas muy variadas situaciones que requieren pormenorizadas y casuísticas descripciones reglamentarias.

\section{A) El ReENVío PENAL NORMAtivo}

De acuerdo con la configuración del delito ecológico, que la reforma de 1983 del Código Penal realiza, la conducta punible se tipifica en razón de la comisión de las agresiones ambientales antes descritas "contraviniendo las Leyes o Reglamentos protectores del medio ambiente». Ello supone introducir aquí para valorar penalmente dichas acciones, un reenvío a la legislación administrativa que da lugar a lo que los penalistas califican como ley penal en blanco (33).

Este tipo de remisión, obligada por lo demás en este caso y que no es nueva en el Código, ha suscitado justificados reparos por parte de algunos tratadistas, que ven aquí una posible desviación del principio de reserva ya aludido de Ley Orgánica en materia penal (34), aunque parece que no existe otra alternativa so pena de tener que incorporar al Código in extenso, o en extracto, centenares y probablemente miles de artículos adicionales, con el paradójico resultado de su casi automática obsolescencia, dada la sucesiva legislación demandada por el progreso de la técnica, los avances, continuamente espoleados por la opinión pública, de la política ambiental, y la adaptación, en el caso de España, de nuestro ordenamiento al de la CEE.

Una vez más se pone de manifiesto que en el Derecho, y en las ciencias sociales en general, hay pocos principios monolíticos, lo

(31) Interpretación coincidente con la de RODRIGUEZ RAMOS: Delitos, loc. cit., p. 843 en nota.

(32) Artículo 81.1 de la Constitución.

(33) Otro criterio es el sostenido minoritariamente por RODRIGUEZ DEVESA que entiende que es necesario la constatación de la infracción administrativa que corresponde a la Administración. con lo que la Ley establecería con este requisito una condición objetiva de perseguibilidad. Delitos contra el medio ambiente, loc. cit., p. 1105.

(34) COBO Del ROSAL VIVES: Derecho Penal. Parte general, vol. II, Valencia, 1981, p. 202. 
que afecta en nuestro caso a la reserva absoluta a la Ley Orgánica de la sanción de conductas con penas de privación de libertad.

Por lo demás la modulación que del indicado principio realiza el artículo 347 bis del Código Penal no implica una flagrante desviación de las garantías implicadas, ya que el Código se pronuncia sobre los aspectos principales y esenciales, dejando a otras normas la complitud de los aspectos no determinantes.

La perspectiva de la pluralidad de fuentes y de la utilización admitida en el Derecho administrativo (35), me parece que tiene también respaldo en el Derecho penal, donde se ha observado la inviabilidad de resolver por ley formal ordinaria todos los conflictos relacionados con la propiedad, por lo que la reserva de ley ordinaria para los derechos no fundamentales habría efectivamente de entenderse en un sentido relativo (36), sin perjuicio de que el bien jurídico protegido y los aspectos sustanciales del tipo penal vengan fijados enteramente por la ley, y que las disposiciones de rango inferior a ésta se ocupen sólo de los aspectos técnicos y ejecutivos (37).

Ante estas dificultades otros ordenamientos, como el italiano y el francés, han optado por mantener estas regulaciones en el ámbito tradicional de los ordenamientos penales-administrativos sectoriales (38). El Código Penal alemán recoge expresamente, como es sabido, la figura del derecho ambiental, pero a diferencia del español, contempla en distintos preceptos la protección del agua, del aire, del suelo y de la naturaleza, ocupándose además específicamente de los más importantes contaminantes (39), con lo que la legislación alemana que, precedentemente, como ha señalado Berinstain (40), seguía pautas equivalentes a las de otros sistemas penales europeos aún en vigor, como vimos, adopta ahora posiblemente el tratamiento más moderno de la materia. No obstante es preferible a nuestro juicio la solución más sincrética y a la postre inevitable del Código Penal español, aunque ello enfrente

(35) Sobre la pluralidad de fuentes en el ordenamiento administrativo vid. por todos GARCÍA DE ENTERRIA y T. R. FERnÁNDEZ RODRigueZ: "Curso de Derecho Administrativo», vol. I, Civitas, Madrid, 1983, pp. 62 y ss.

(36) COBO DEL ROSAL VIVES: Derecho penal, vol. 1, pp. 73 y ss.

(37) CASABO: La capacidad normativa de las Comunidades Autónomas, loc. cit., p. 260.

(38) Vid. DE LA CUESTA: Protección penal, op. cit., pp. 923 y ss.

(39) Vid. DE LA CUESTA op. cit., pp. 919 y ss., y expresamente sobre el tema de este autor, "La ley alemana de reforma del Código Penal para la lucha frente a la criminalidad contra el ambienten, en Cuadernos de Política Criminal núm. 18/1982, pp. 652 y. ss. También BACIGALUPO: "La instrumentación penal del medio ambiente», en Estudios penales y criminológicos, Santiago de Compostela, 1982, y TIEDEMANN: "El nuevo Derecho penal español del ambiente en comparación con el Derecho penal alemán del ambienten, en La droga en la sociedad actual, op. cit., pp. 291 y ss.

(40) "La reforma del Código Penal alemán», en Anuario del Derecho Penal, 1961, pp. 371 $y$ siguientes. 
las comprensibles reticencias de quienes consideran que la técnica de los tipos penales en blanco debe evitarse en aras de la constitucionalidad y de la legalidad (41).

\section{B) LA LEGISLACIÓN ADMINISTRATIVA}

El inevitable concurso de la legislación no penal para la determinación de las conductas sancionadas con normas de este carácter plantea no sólo el problema de delimitar los recíprocos campos de acción, sino el de las consecuencias del autónomo funcionamiento de ambos ordenamientos $y$, en concreto, la posibilidad de que recaigan sanciones con distinta causa, penal y administrativa, sobre el mismo hecho, lo que, salvo minoritarias opiniones (42) la doctrina penalista rechaza por considerarlo contrario al principio non bis in idem (43).

Tal conflicto de normas sería inevitable si la constatación de la infracción administrativa, lo que no comparto, hubiera de ser previa a la iniciación del proceso penal (44), pero aun sin ello en la mayoría de los casos habrán mediado previamente actuaciones administrativas correctivas. Intervenciones de este orden se contemplan por el Código como presupuestos de la agravación de la pena: desobedecimiento de órdenes expresas relacioadas con la actividad, por lo que se ha propuesto que en tales casos el «Juez penal tenga en cuenta en su margen de arbitrio, a la hora de determinar la pena la sanción administrativa impuesta y cumplida por el reo, con el fin de reducir la pena en una compensación racional» (45), sin perjuicio por supuesto que en el caso inverso, seguramente mucho menos frecuente en la práctica, de que sea previa la sanción penal, se enerve la represión administrativa.

Las disposiciones administrativas concurrentes, deberán venir encabezadas por una norma con rango de ley formal ordinaria, de acuerdo con lo dispuesto en el artículo $\mathbf{5 3 . 3}$ de la Constitución, al no ser el derecho al ambiente un derecho fundamental, aunque, como se ha adelantado, también sean invocables los reglamentos que las desarrollen y que el propio artículo 347 bis invoca.

Estas disposiciones pueden tener en cuanto a su origen la siguiente naturaleza.

(41) En este sentido también DE LA CUESTA: op. cit., p. 931.

(42) RODRIGUEZ DEVESA: op. cit., p. 1161.

(43), Lo que también asumen sin excepciones los administrativistas como no podía por menos tras la Sentencia del Tribunal Constitucional de 30 de enero de 1981. Vid. GARCIA DE ENTERRIA: "La Constitución como norma y el Tribunal Constitucional», Civitas, Madrid, 1981, apéndice, pp. 245 y ss.

(44) Pasándose el tanto de culpa a los Tribunales por la Administración, RODRíGUEZ DEVESA op. cit., p. 1105.

(45) RODRíguez Ramos: Delitos contra el medio ambiente, loc. cit., p. 843. 


\section{a) Las Comunidades Europeas.}

A efectos del derecho interior la CEE no constituye por lo general un nivel normativo independiente, ya que la legislación emanada de los órganos de la Comunidad, y concretamente de la Comisión, vía Directivas, obliga inmediatamente a los Estados que deben acomodar la legislación nacional a estos mandatos. Sin embargo, se admite el efecto directo $y$, desde luego, tienen esta incidencia los Reglamentos de la CEE, que a estos efectos deberán ser tenidos en cuenta por los Jueces con las matizaciones que veremos en lo que respecta al Derecho penal.

Frente a la tesis inicial de que el Derecho comunitario vincula sólo a los Estados, se ha venido sentando por obra de la jurisprudencia del Tribunal de Justicia, la doctrina del efecto directo que reconoce a las normas comunitarias propia virtualidad superadora de los condicionamientos del Derecho interno (46).

Esta construcción, que arrancó de la Sentencia Van Gend en Loos de 1963 (47), es fácilmente acomodable a las características de los Reglamentos, que de acuerdo con el artículo 189 del Tratado son obligatorios y directamente aplicables en todo Estado miembro. Distinto parecería ser el caso de las Directivas que en principio irían dirigidas inmediatamente sólo a los Estados, dejando en libertad a estas instancias en cuanto a forma y medios (48). Sin embargo, el Tribunal de Justicia, a partir de las Sentencias Grad y SACE de 1970, ha venido también progresivamente extendiendo el efecto directo a las Directivas vía Sentencias que establecen las condiciones generales para la producción de estas consecuencias. «En todos los casos en que las disposiciones de una Directiva aparezcan desde el punto de vista de su contenido como incondicionadas y suficientemente precisas, estas disposiciones pueden ser invocadas en defecto de medidas de aplicación adoptadas en los plazos establecidos, en contra de toda disposición nacional no conforme a la Directiva, o en tanto que son susceptibles de definir derecho que los particulares pueden hacer valer respecto al Estado» (49). Estas circunstancias cuadran perfectamente a la mayoría

(46) Vid. una reseña de los principales fallos del Tribunal de Justicia en este sentido, en BOUlouls Chevalier: Grandes arrêts de la Cour de Justice des Communités Européennes, I,

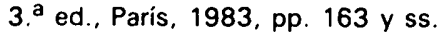

(47) Vid. MARQUÉS: "Jurisprudencia del Tribunal de las Comunidades Europeas. El efecto directon, en Revista Valenciana de Estudios Autonómicos, 2/1983, pp. 247 y ss.

(48) Según el artículo 189 del Tratado CEE.

(49) Cit. MUÑNOZ MACHADO: Los principios de articulación de las relaciones entre Derecho comunitario y el interno y las garantías jurisdiccionales para su aplicación efectiva, en GARCíA DE ENTERRIA y otros: "Tratado de Derecho comunitario europeo», vol. I, Madrid, Civitas, 1986, p. 514, con base en las Sentencias Ratti de 1979, Comisión V, Bélgica de 1980 y Ursula Becker de 1982. 
de las Directivas comunitarias sobre el ambiente, precisas $y$ complejas, que dejan poco o ningún margen al arbitrio estatal (50). Aunque el Tribunal de Justicia no se ha pronunciado expresamente sobre la aplicación a este ámbito del efecto directo, sí ha sentado con energía la supremacía del ordenamiento ambiental comunitario sobre los nacionales (51).

Parece que en principio la asimilación del Derecho comunitario por el Derecho penal de los Estados ofrecerá mayores dificultades ante el no discutido monopolio de éstos para regular las cuestiones que afectan a la libertad de sus súbditos (52), a lo que, sin embargo, se opone la disponibilidad comunitaria sobre la legitimidad o ilegitimidad de determinadas conductas.

El conflicto se ha zanjado no sé si con general consenso, un tanto salomónicamente, en el sentido de reconocer a las instituciones comunitarias capacidad para enervar las leyes penales nacionales, incluso a través de Directivas (53), pudiendo revocarse prohibiciones e incriminaciones contrarias con las normas adoptadas dentro del ámbito de competencias comunitarias, pero no establecerse nuevas penas (54). Todo ello exige, por supuesto, un ejercicio complicado de adaptación a cada caso, que ya se ha intentado para algunas materias concretas (55), resultando particularmente difícil en la que nos ocupa, dada la gran extensión reglamentaria de los ordenamientos nacionales implicados (56).

La disponibilidad para el Derecho comunitario del ordenamiento penal español en materia ambiental es mucho más amplia que para Francia e Italia, donde rigen exclusivamente leyes penales especiales. El reenvío que nuestro Código realiza al respecto a lo dispuesto

(50) Vid. López RAmón: La política de Medio Ambiente de la Comunidad Europea y su incidencia en el Derecho español, en GARCiA DE ENTERRÍA y otros: Tratado de Derecho comunitario, vol. III, p. 539.

(51) Comisión v. República Italiana 1980, Comisión V. Reino de Bélaica 1982, cit., HUESA: "La Jurisprudencia del Tribunal de Justicia Comunitaria en materia de protección del medio ambiente", en Revista Valenciana de Estudios Autonómicos núm. 7/1987, pp. 447 y ss.

(52) Vid. al respecto J. J. DíEZ: Derecho penal internacional, tesis doctoral, desgraciadamente inédita en estos momentos.

(53) PEDRAZZI: «Droit communantaire et Droit penal des Etats membres», en Droit Communantaire et Droit penal, Colloque du 25 octubre 1979, Giulfré Milano, 1981, p. 63.

(54) DECOCQ: "Le conflict entre la regle Communanteire et la regle penalle interne», en Droit Communantaire et Droit penal, cit., p. 31.

(55) Así, GialCalone: "E indiferent, per il Diritto Comunitari lo statuto penale dege, operatori bancari», en Foro Italiano núm. 9/1987, pp. 345 y ss.; RIZIGER: «Rapports entre le Droit penal français et le Droit Communantaire», en Gaizette du Palais, núms. 96-98/1986, pp. 2 y SS., y GIOVANNI: «Profil, penalistic, nella normativa d'attuazione della Secondo Directiva CEE in materia societarian, en Foro Italiano núm. 6/1986, pp. 321 y ss.

(56) Vid. para ttalia DETTORI: "Aspects de droit penal de la loi italienne pour la proteccion des aux coutre la pollution et Droit Communantairen, en Droit Communantaire et Droit penal, cit., pp. 125 y s., y RASTRELLI: Quelques observations liminaires sur les rapports entre le Droit Communantaire et le Droit penal italien de la pollution atmospherique, op. cit., pp. 175 y ss. 
en leyes y reglamentos, obliga a tener en cuenta lo dispuesto por el Derecho comunitario, que puede ampliar así las circunstancias delictivas, incluso vía Directiva con efecto directo, lo que habrá de apreciar el Juez penal, que asumirá así una adicional carga a sus nada desdeñables dificultades en este campo.

\section{b) Normativa estatal.}

Será la más numerosa, al menos en cuanto a leyes troncales, ya que por el juego de los criterios constitucionales de distribución de competencias entre el Estado y las Comunidades Autónomas corresponde al Estado la legislación básica sobre montes y protección del medio ambiente (57), lo que se reitera para sectores concretos como los cursos fluviales que afecten a más de una Comunidad Autónoma, el derecho minero, etc. (58).

\section{c) Comunidades Autónomas.}

Más allá de la legislación básica que incumbe al Estado, las Comunidades Autónomas pueden legítimamente sancionar Leyes que afectan a sus intereses privativos y dictar normas adicionales de protección (59) además de las competencias de que pueden disponer de acuerdo con sus Estatutos conforme con lo previsto en el artículo 148 de la Constitución (60), lo que ha respaldado expresamente el Tribunal Constitucional en relación con los espacios naturales protegidos (61) y la explotación de minas a cielo abierto (62). Aunque, por supuesto, a las Comunidades Autónomas les está vedado el promulgar leyes que impliquen sanciones penales monopolizando el Estado estas represiones (63), sí pueden

(57) Artículo 149.23.

(58) Vid., para una panorámica de la distribución competencial en materia de medio ambiente mi trabajo. Ambiente y recursos naturales. El sistema institucional, cit., pp. 24 y siguientes.

(59) Artículo 143.1.23.

(60) Vid. CASABO: La capacidad normativa de las Comunidades Autónomas, pp. 240 y ss.; RODRIGUEZ RAMOS: "El medio ambiente en la Constitución Española», en Derecho y medio ambiente, MOPU, Madrid, 1981, pp. 31 y ss.; T. R. FERNÁNDEZ RODRIGUEZ: «EI medio ambiente en la Constitución Españolan, en Documentación Administrativa núm. 190/1981, pp. 337 y ss., y MUÑOZ MACHADO: "La distribución de competencias entre el Estado y las Comunidades Autónomas en materia de medio ambienten, en Documentación Administrativa núm. 190/1981, pp. 351 y ss. "Derecho público de las Comunidades Autónomas», Civitas, Madrid, 1982, pp. 560 y ss.

(61) Sentencias de 23 de noviembre y 31 de diciembre de 1981, comentadas por SosA WAGNER: «Espacios naturales protegidos y Comunidades Autónomas», en Revista Española de Derecho Administrativo núm. 36/1983, pp. 343 y ss.

(62) Sentencia de 4 de octubre de 1982. Vid. SOSA WAGNER: Espacios naturales, cit., p. 348, y especialmente QUINTANA: La repercusión de las actividades mineras en el medio ambiente. Su tratamiento jurídico, Madrid, 1987.

(63). Artículo 81.1 de la Constitución. 
en materia ecológica «establecer infracciones y sanciones de carácter administrativo (64), capacidad que han ejercido en diversos casos, especialmente en el área de la Comunidad Autónoma de Cataluña, en relación, entre otros, con la atmósfera (65), residuos (66), explotaciones a cielo abierto (67) y saneamiento (68).

\section{d) Municipios.}

La justicia penal deberá también manejar, para precisar las conductas punibles, los reglamentos y ordenanzas municipales que en algunos supuestos constituyen el único soporte normativo aplicable, caso de los ruidos urbanos y en otros un complemento imprescindible, ya que la legislación estatal carece de desarrollo, supuesto de los residuos sólidos (69), salvo en lo que afecte también a las aguas subterráneas. Pero tampoco esto es una novedad $y$ hay en el Código otras conductas cuya valoración precisa de estos soportes.

\section{LA APARENTE INEFICACIA DEL DELITO AMBIENTAL}

Hasta la fecha, la aplicación práctica de esta nueva figura delictiva ha patentizado su escasa operatividad. Es significativo que en los cinco años de vigencia sólo haya hasta ahora recaído una condena por este tipo de conductas. La de la Audiencia Provincial de Barcelona de 23 de febrero de 1988 (70), en la que se declara probado una agresión al equilibrio ecológico, que afecta a unas treinta mil hectáreas, condenando al director de la central térmica de Cers a la pena de un mes de arresto y una multa de treinta mil pesetas y al pago de cerca de tres millones en concepto de indemnización por daños en cultivos y ganados a los seis vecinos denunciantes, declinando pronunciarse, como es lógico, sobre la imposición de medidas correctoras, pese a haberse acreditado la superación constante de los niveles legales de emisión. Sin duda, que en este caso influyeron larvadamente los condicionantes a que

(64) Definitivamente, CASABO: La capacidad normativa, cit., p. 260.

(65) Ley 22/1983, de 9 de noviembre, sobre protección del ambiente atmosférico.

(66) Ley 6/1983, de 7 de abril, sobre residuos industriales.

(67) Ley 12/1981, de 24 de diciembre, sobre protección de espacios de particular interés natural afectados por actividades extracticas, y Decreto 343/1983, de 15 de julio.

(68) Ley 5/1981, de 4 de junio, sobre desarrollo legislativo en materia de evacuación y tratamiento de aguas residuales, y Decreto 305/1983, de 13 de julio.

(69) Vid. ad exemplum el Código municipal de limpieza viaria y gestión de residuos de Barcelona, aprobado en 18 de marzo de 1983, denominado Ordenánzas de la Nenteja, Ayuntamiento de Barcelona, 1983.

(70) Ponente señor don José Antonio Oscariz. 
luego nos referiremos, ya que se alegó la imposibilidad técnica y económica de introducción de las medidas correctoras precisas para evitar la contaminación.

Los tratadistas del Derecho penal ya habían anticipado estas consecuencias y no regatearon críticas a las soluciones arbitradas para perfilar este precepto, llegándose a afirmar con indudable energía que «no se hubiera hecho mejor si deliberadamente se hubiera buscado la más absoluta ineficacia» (71). Posiblemente estas críticas sean fundadas en lo que respecta a los mecanismos jurídicos penales, pero es dudoso que pudieran conseguirse resultados espectaculares, en términos de eficacia sancionadora y contundencia en la erradicación de estas conductas, dadas las circunstancias que afectan al delito ambiental.

\section{A) LAS DIFICULTADES PRESENTES}

Entre los obstáculos que entorpecen la precisión del comportamiento ambiental, penalmente antijurídico, no incluyo por mi parte la ausencia de una Ley general del ambiente (72), pese a que efectivamente la dispersión de la legislación y la amplitud normativa no favorece ciertametne la preceptiva identificación y acreditación de la infracción de la legislación sectorial. Una Ley general del ambiente está condenada a rápida periclitación, salvo que sea tan ambigua que para poco sirva la experiencia de los ordenamientos que han adoptado normas de este tipo: Gran Bretaña y Colombia, entre otros, acreditan la inoperancia de estos textos. Sí en cambio me parecen relevantes, negativamente, los siguientes factores:

- El hecho de que múltiples acciones de transcendencia contaminadora sean regulares, para la Administración por contar con las autorizaciones oportunas, no existiendo, por tanto, infracción de Reglamentos. De hecho muchas reparaciones han de ser solicitadas en vía civil, negándose por cierto los tribunales de esta índole a exonerar de responsabilidad a los causantes de los daños no obstante la legalidad administrativa de estas conductas (73).

(71) RODRIGUEZ DEVESA: loc. cit., p. 1107.

(72) Lo que ha sido reclamado también por algunos administrativistas, PÉREZ MORENO: «Ley general $y / o$ leyes sectoriales para la protección del medio ambiente», en Documentación Administrativa, núm 190/1981, pp. 441 y ss., y del mismo con ESCRIBANO y LóPEZ GONZÁLEZ: "Desarrollo legislativo de la Constitución en materia de protección del medio ambiente", en Revista de Administración Pública núm. 103/1984, pp. 361 y ss. Contra LóPEZ RAMÓN: «ldeas acerca de la intervención administrativa sobre el medio ambiente», en Documentación Administrativa núm. 190/1981, p. 42, y La política de medio ambiente de la Comunidad Europea, loc. cit., p. 543.

(73) Me remito a mi trabajo «Jurisprudencia ambiental del Tribunal Supremo español desde el cambio políticon, en Revista de Administración Pública núm. 108/1985, pp. 189 y ss. 
- No es infrecuente el que el causante del daño sea la propia Administración, vertidos municipales, por ejemplo, con lo que la identificación del agente personalmente responsable, siempre problemática en estos casos, ofrece mayores dificultades, máxime si se trata de omisiones, lo que se da reiteradamente, plantas depuradoras que no funcionan, vertederos de basuras que no se cuidan, o no se proveen, etc.

- Problemática comprobación y acreditación de las relaciones causa-efecto y de la identificación de responsabilidades, lo que sólo en casos muy significativos suelen aflorar: grandes catástrofes. La acreditación de estas conexiones cuando existen varios contaminadores potenciales se enfrenta con grandes dificultades técnico-prácticas, lo que inhibe, como es lógico, el pronunciamiento judicial (74).

- Efectos acumulativos de la contaminación resultante, que puede ser de notoria importancia y nocividad, pero ser imputable a la suma de los efectos de múltiples focos sin que cada uno de ellos tenga relevancia delictiva propia.

- La inevitable limitación de la calificación delictiva, a las contaminaciones graves, esta restricción del Código, y la indeterminación adicional que introduce, ha sido también censurada por la doctrina. Por supuesto que podría haberse prescindido de tal requisito, pero en la práctica la situación no habría cambiado, so pena de, en el otro extremo, ampliar excesivamente el área sancionable, piénsese que el fumar un cigarrillo en un local público reuniría los condicionamientos precisos para ser calificado como delito ambiental.

- El lastre de las situaciones precedentes. Las nuevas industrias y actividades no son, por lo general, contaminantes, pero sí lo son instalaciones antiguas y además poco rentables. Ya sabemos que frente al legislador no hay derechos adquiridos, pero sociológica y políticamente se presentan aquí rémoras no desconocibles, sobre todo si hay importantes consecuencias económicas y aun sociales implicadas, así se ha logrado un aplazamiento parcial para España, según parece de la normativa comunitaria de grandes quemadores, lo que supone disminuir en un 50 por 100 una inversión estimada de 600.000 millones de pesetas.

(74) Asi la sentencia del Tribunal Supremo de 19 de junio de 1980 no pudo acreditar la relación causal entre los daños sufridos por una mejillonera y los responsables de los derrames de petróleo que los produjeron, en los que podian estar implicados varios buques que navegaban por la misma bahia. 


\section{B) LOS ATENTADOS AMBIENTALES NO CUBIERTOS}

Se ha imputado a la Reforma del Código el no haber incluido en el delito ambiental conductas que afectan negativamente a otros recursos naturales cuya irracional utilización proscribe también la Constitución, pero recordemos que no todas las infracciones de este tipo deben necesariamente ser sancionadas penalmente $y$, por otra parte, los perjuicios causados a la flora y fauna vía contaminación están contemplados por el Código.

Tampoco estimo que, al configurarse la infracción ambiental como un delito de resultado mediante la creación de un peligro concreto, no resulte sancionada por esta vía la materialización del riesgo determinante del daño, lo que efectivamente tiene cobertura adicional en otros artículos del Código. Pero es que, de producirse lesiones en determinados bienes jurídicos como consecuencia de la contaminación, habría lugar a la automática probanza de la creación del peligro, lo que daría lugar a la acreditación de la comisión del delito.

Sí pudiera haberse previsto la sanción de las siguientes conductas:

- Atentados contra el suelo, vía provocación de incendios o prácticas de desforestaciones no autorizadas. Si bien, y pese a los defectos sustanciales y sistemáticos que puedan argüirse, estas conductas han sido tipificadas penalmente tras la reforma parcial en relación al delito de incendio introducida por la Ley Orgánica 7/1987, de 11 de diciembre, en los artículos 553 bis, a); 553 bis, b), y 553 bis c). En particular, algunas de las agravaciones previstas en el artículo 553 bis, b), afectan paradigmáticamente a lo que en este trabajo concebimos como "medio ambiente», al castigar con graves sanciones aquellos supuestos de incendio, de los cuales use deriven grandes o graves efectos erosivos en los suelos (circular segunda), o se alteren significativamente las condiciones de vida animal o vegetal (circular tercera), o, en todo caso, cuando ocasione grave deterioro o destrucción de los recursos afectados (circular cuarta).

- Transportes de mercancías peligrosas (75), una de las más arriesgadas operaciones ambientales de nuestros días y que preocupan en todos los medios europeos, sobre todo si tiene implicaciones transfronterizas, a veces con destino a

(75) Si previsto en el Código Penal alemán, artículo 330. 13. Vid. DE LA CUESTA: Protección penal, op. cit., p. 922. 
países del Tercer Mundo. Sólo lasamente estas conductas encajarían en la figura del "provocador».

- Adición de energía limpia, el efecto de choque en los desembalses que producen una gran mortandad piscícola.

- Fabricación de utillaje de transporte doméstico o industrial no autorizado y de productos prohibidos, insecticidas, productos clorados, etc. Aquí sí podría encajar mejor la figura del provocador.

Operaciones no autorizadas relacionadas con la energía nuclear, que constituyen una importantísima causa de generación de riesgos, recordemos el caso de Chernobyl, que ha conmovido a la humanidad. Estas conductas, incluyendo la manipulación no autorizada de combustibles nucleares y la no restitución de residuos radiactivos están también expresamente contemplados en el Código penal alemán (76).

\section{Balance}

Los, sin duda, estadísticamente pobres resultados de la Reforma de 1983, en lo que al delito ambiental se refiere, pueden ser contrapesados por otras consecuencias positivas de problemática patentización, como el efecto disuasorio de la amenaza penal.

Por otra parte, los más cualificados especialistas en estas cuestiones han puesto de relieve la inviabilidad de hacer descansar sólo sobre el Derecho penal la cobertura defensiva ambiental de la sociedad, máxime cuando el efecto preventivo es aquí decisivo (77). Una política criminal sobre el medio ambiente, se ha dicho, ha de comenzar por reconocer que el acento ha de colocarse en las medidas preventivas de tipo administrativo y civil (78), en lugar de caer en el recurso evasivo, que brillantemente se ha descrito como huida al Derecho penal (79).

Recordemos, no obstante, en favor del precepto comentado, que ha sabido definir las nerviaciones básicas del ambiente, y digamos también que ha sido receptivo hacia las más conocidas manifestaciones de las agresiones ambientales agravándolas: clandestinidad, vertidos nocturnos en los ríos, emisiones de gases polvos durante la noche; reiteraciones: vertidos contaminantes

(76) DE LA CUESTA: op. cit., p. 922.

(77) RODRIGUEZ RAMOS: «Presente y futuro de la protección penal al medio ambiente», en Derecho y medio ambiente, Madrid, 1981, pp. 251 y ss., y «Alternativas a la protección penal del medio ambiente», en Estudios penales y criminológicos, Santiago de Compostela, 1981, pp. 191 y ss.

(78) GONZÁlez DEVESA: op. cit., p. 1112

(79) ROdRíguez RAMOS en COBO DEL ROSAL BAJO: Comentarios, vol. I, p. 269. 
sistemáticos en otras épocas sancionados con la máxima, pero reducida, multa administrativa; desobediencia: falta de implantación de medidas correctoras, no utilización de depuradoras y filtros; desinformación: no facilitación de documentos a inspectores; falta de autorización industrial, también en el medio rural y en explotaciones pequeñas agropecuarias.

El presente trabajo constituye la aportación de su autor a la obra-homenaje al profesor Antonio Beristain. 
REALA-1988, núm. 238. MARTIN MATEO, RAMON. EL DELITO AMBIENTAL. REFLEXIONES DESD...

REALA-1988, núm. 238. MARTIN MATEO, RAMON. EL DELITO AMBIENTAL. REFLEXIONES DESD... 